\title{
Human Trafficking: A Human Rights Oriented Approach
}

\author{
Ardeshir Farrokhzad ${ }^{1}$ \\ ${ }^{1}$ Ankara University, Ankara, Turkey \\ Correspondence: Ankara University, Ankara, Turkey. Tel: 98-919-591-5724. E-mail: ardeshirferd@gmail.com
}

Received: June 19, 2017

Accepted: July 19, 2017 Online Published: September 5, 2017

doi:10.5539/ilr.v6n1p132

URL: https://doi.org/10.5539/ilr.v6n1p132

\begin{abstract}
Men's struggle for survival has never been so intense, and they have been able to save themselves from the physical pain inflicted by fatal war weapons. However, the invasion on men's dignity in different forms including organ smuggling, experimental dummy, slavery, forced prostitution, etc. has followed an unprecedented rate in terms of inflicting misery and suffering millions of lives across the universe in the contemporary world. Most probably, "Right to Dignified Life" could be considered the most salient objective of Human Rights Principle. It is also a justified fact that the tragic misery of contemporary man has to do with obliteration of the same fundamental principle underpinning Human Rights. More importantly, it is not merely sufficient for a man to survive. Man requires self-dignity, voice and remedies for achieving happiness and welfare, otherwise he/she is nothing but a mere physical existence. The contemporary man that has undergone such huge amount of human tragedies and sufferings increasingly loses its control over its own body, work and movement, and many accede to the fact that the most obvious reason is human trafficking.
\end{abstract}

Keywords: human trafficking, human rights, persons, smuggling

\section{Introduction}

Nowadays, human trafficking is one of the most profitable ventures in the world, and based on the statistics reported by U.S. Federal Bureau of Investigation, human trafficking generated a total of 9.5 billion dollars in revenue in 2005 (http://www.state.gov/g/tip/rls/tiprpt/2005/). Similarly, 600,000 to 800,000 people are trafficked annually across international borders (Ibid). Although the presentation of accurate data is always elusive, total people trafficked within or outside a nation could be even much higher. And it is not that states across the world have not fried to acknowledge this problem and act reasonably; at least they thought they were reasonable policy of combating trafficking. But even with such huge sum, commitment, mobilization trafficking is far from getting curved. Hence, now it is not just that trafficking is the only problem but the mystery involved in its definition, prohibition and approach has come under serious scrutiny.

Failing to identify the actual trafficking from other closely related phenomena such as migration, smuggling of people, prostitution has meant that an effective and coherent force against trafficking is missing. Authorities across the globe still stick to the outdated and traditional definition of trafficking thereby failing in their main objective of controlling the calamity. Similarly, it is found that very little attention is given to the reasons of trafficking, because of which trafficking process is getting more and more improvised and getting beyond the reach of law.

Perhaps, within this colossal of mysteries and questions also one thing all forget and take for granted is the human face behind trafficking, the people who get trafficked. Up to now societies take trafficked, as partner of crime. Even after getting over the miseries of trafficking the trafficked have to endure another battle for their existence in the society. Most of the times people are insensitive about the trauma and pain that a trafficked has to suffer and the losses that they bear. Trafficking as a process as such may involve the person for some time but the trauma that gets ensued after coming out is no less than the trauma during trafficked period. Hence the most devastating and cataclysmic error in approaching trafficking is the negligence of the trafficked after they are free from the control of perpetrators and the definition of trafficking in which, everyone draw boundary of trafficking as including the period between the seize of liberty of the person and the release of the person. Hence a new approach, which not only can serve in eradicating the root cause of trafficking but can also give care, rehabilitation and belief to the people who are victim of trafficking, thereby making society more sensitive towards rights of everyone, is inevitable. Because if anything that can stop this scale of human degradation will be the respect of mutual existence and rights. 
Focus of the Study as it must be clear by now that midst of this grave problem, haphazard sensitivity and low priority to the rights has added an impetus in the search of better approach regarding trafficking. Hence the paper focuses on the possible and resolute approach to the trafficking. And in this regard the paper focuses on the rights of the person trafficked, i.e. this paper focuses on the rights based approach to the trafficking in person. Within this approach the paper tries to define the various rights in question during and after trafficking in persons.

\section{Objective of the Study}

The present paper's objectives include:

1) To put forward a conceptual framework regarding trafficking in persons,

2) To study the Human Rights Approach to Trafficking,

3) To analyze the national legal mechanisms underpinning rights oriented-approach to trafficking.

\section{Limitation of the Study}

Undoubtedly, the scope of trafficking exceeds what the current paper seeks to fathom. Due to the limited space and other limitations underlying the current paper, it does not discuss and elaborate on the major roots of trafficking and the existing procedures and strategies to prevent trafficking. Furthermore, the paper does not explicate the international legal mechanism to combat trafficking.

\section{Trafficking: A Conceptual Framework}

It has been a very long time that different scholars have presented different definitions on human trafficking, and although "The definition of trafficking continues to the subject of debate, and there is no conclusive or even commonly agreed upon definition globally, regionally or even nationally". (Save The Children Alliance (UNICEF), Trafficking of Women and Children in South Asia: Taking Stock and Moving Ahead, A Broad assessment of Anti- Trafficking initiatives in Nepal, Bangladesh and India, 1999 (P. 30)) This is because most of the time people has been overwhelmed by the ambiguity of other very closely related phenomena similar to trafficking. In this regard, migration, smuggling of people and prostitution hold particular importance. It is highly challenging and even impossible to examine the above processes in isolation from each other, and even if we are allowed to mix them with each other while studying, the final result would nothing except for the failure to fulfil the pre-determined objectives. Hence sometimes "mixing trafficking and migration or other processes can be counter-productive in addressing the complex trafficking issues." (Md. Azad, Ambiguities and Confusions in the Migration- Trafficking Nexus: A Development Challenge, 2005). Thus, the most crucial point while defining trafficking is the fact that the term should be defined properly and distinctively, and no ambiguity be remained in the distinction between the definition of trafficking and some other social phenomena such as smuggling of people, prostitution or migration. Traditionally, trafficking has been applied synonymously with prostitution and the perception is still somehow prevalent among us. Many still reinstate that trafficking is the same prostitution, and the fact is that the issue can be also true. "In international law, the historical understanding of trafficking has been revolved primarily around feminist movements across borders in the area of prostitution." (Save The Children Alliance (UNICEF), Trafficking of Women and Children in South Asia: Taking Stock and Moving Ahead, A Broad assessment of Anti- Trafficking initiatives in Nepal, Bangladesh and India, 1999 (P. 31). However, such conflation has a variety of unwanted consequences, to the extent that, trafficking to fulfill other purposes including forced marriage, domestic labor, and trafficking in other unregulated industrial and agricultural sites, etc. remain prominently overlooked by anti-trafficking groups. As a result, and under such condition, the real picture can be seen only when some distance is kept between trafficking and prostitution. This is because such conflation can never take into account all victims suffering from trafficking at once. Similarly Trafficking also needs to be understood as a different issue than migration and smuggling of people. Trafficking is also migration, but it is an involuntary migration, which takes place within the migratory space. In fact, both trafficking and migration proceed in an identical way, both involve 'recruitment and transportation' (Ibid) as the common initial phases. But the debate lies in the question of accurate place and instance for the bifurcation of trafficking and migration. People may start their journey voluntarily but with the deceit and coercion they may get trafficked at the end. So a thin line must be identified which can turn voluntary migration into trafficking. And in absence of such bifurcation "...the link between trafficking and migration presents another complexity presenting both political and substantive obstacles to resolution of the trafficking problem." (UN Secretary General's Report on "Trafficking in women and Girls" presented at the 58th Commission of Human Rights (2002) (www. unhchr. ch))

Now with some clarity, a resolute definition of trafficking can be addressed. Perhaps, in this regard the most authentic definition of trafficking would be, "the recruitment, transportation, transfer, harbouring or receipt of persons, by means of the threat or use of force or other forms of coercion, of abduction, of fraud, of deception, of the abuse of power or of a position of vulnerability or of the giving or receiving of payments or benefits to achieve 
the consent of a person having control over another person, for the purpose of exploitation and consent of a victim of trafficking in persons to the intended exploitation ... shall be irrelevant where any of the means set forth have been used" (Article 3 ( $a \&$ b) of Protocol to Prevent, Suppress and Punish Trafficking in Persons, Especially Women and Children, Supplementing the United Nations Convention Against Transnational Organized Crime (2000) [Palermo Protocol]) This definition of the Palermo Protocol marks a major paradigm shift in the concept of trafficking; now trafficking has much broader scope. The most significant feature of this definition is that it recognizes exploitation as the most important element in trafficking rather than movement across a border, which is significant because when someone talks about Rights Based approach to the Trafficking it is not the technical details or mechanisms how trafficking takes place rather it is the person who is trafficked is important. Similarly, by making consent of the victim irrelevant in trafficking it has stopped the fallacy that use of force can only amount to trafficking, thereby expanding the scope of punishing the perpetrators who use innovative and improvised (Now days it is found that traffickers most of the times marry a girl to take her across the border, promise job, new opportunity, places in order to traffic them, they don't indulge in forced trafficking.

Employment-induced Migration through Missing 5.4\% Force (abduction) $6.4 \%$ False Visits $16.3 \%$ Fraudulent Marriage $12.3 \%$ Dalai (Broker) $59.4 \%$, source: Dr. Monique Hennink, Sex Trafficking in Nepal: Context and Process, Opportunities and Choices working Paper 2004) way for trafficking people.

But only the substantive definition of trafficking cannot serve in totality, the real objective of addressing trafficking. In order to conceptualize the whole picture of human trafficking it is imperative that the trafficking process is judged aligning it alongside the misery and suffer of victims. After somebody gets trafficked the "person no longer has control over what type of work they do, their work environment and the conditions of work, their freedom of movement and so forth.” (Md. Shahidul Haque, Right Based Approach to Human Trafficking, 2005) So trafficking is not only the process involving the procurers and trafficked for some purpose but also the grave violation of basic Human Rights of the trafficked, which most of the times result into long term trauma both physical as well as psychological.

\section{Rights Based Approach to Trafficking}

As trafficking has always been understood only within the limited scope of the 'Physical loss of control of the victim due to threats, debt, bondage, etc' so authorities seldom if ever gave any impetus in perceiving trafficking in a more humane way. And even if they sometimes tried to address the issue they "mostly focused on the protection of the human rights of trafficked persons and - to a lesser extent - on prevention" (Marjan Wijers, An exploration of the meaning of a human rights based approach to trafficking, Alliance News, 2004 (pg 1)) But rights based approach endeavors to attach new dimension in tackling trafficking. Rights based approach to trafficking also gives primary importance to the suffering and restitution of the victims of trafficking. Along with that it also gives particular importance to the understanding of reasons, process, and consequences of the trafficking through the victim's Human Rights perspective.

Human Rights-oriented approach to trafficking stands on the notion that human trafficking is both a cause and effect of human rights violations. As the former UN High Commissioner for Human Rights, Mary Robinson alleges, "trafficking is a cause of human rights violation because it violates fundamental human rights, such as the right to life, the right to dignity and security, the right to just and favorable conditions of work, the right to health, the right to equality and the right to be recognized as a person before the law. It is a consequence because it is rooted in poverty, inequality and discrimination" (Mary Robinson speech on "Women's Rights are Human Rights", Geneva 2000, www. unhchr. ch/html/menu2/womenmb2000.html). Thus, it is of critical significance to place the protection of all human rights at the center of any action taken to block and terminate trafficking, and this is what exactly the rights based approach of trafficking is meant to do. But rights based approach is not a methodology on its own but a way of improving the existing methodologies and approaches. (Md. Shahidul Haque, Right Based Approach to Human Trafficking, 2005) It can present a conceptual and normative structure with the potential to give direction to the further development of policies pertinent to trafficking. "it offers a framework to monitor and evaluate anti-trafficking policies, practices and actions for their real and potential impact on trafficked persons and other groups affected" (Marjan Wijers, An exploration of the meaning of a human rights based approach to trafficking, Alliance News, 2004 (pg 1-2) In short, rights based approach simply injects principles of Human Rights in building perception about trafficking.

\section{Issues in Rights Based Approach to Trafficking}

As with the rights, the existence of some duty-holders is of high significance, and in terms of the realization of Human Rights, the primary accountability rests with the state in which the person concerned lives. So when anybody gets trafficked, the state is held accountable to protect such person. Hence the first key area of rights 
based approach to trafficking is the protection and assistance of the trafficked persons. In this too rights based approach first demands that state acknowledge trafficking as the violation of Human Rights, so that while assisting the victims state not only protects the rights of the victims but also ensures the proper redress of encroached rights.

In line with this, rights of the trafficked include, (On the basis of the (a) Recommended Principles and Guidelines on Human Rights and Human Trafficking, Report of the United Nations High Commissioner for Human Rights to the Economic and Social Council (Principles 7-11) Persons, Global Alliance Against Traffic in Women) access to justice, private actions and reparations; procedural protections in court cases, witness protection and legal assistance; access to temporary and, if necessary, permanent residence status; access to social, psychological and health care and help with a safe, and to the extent possible voluntary, return to their country of origin; immunity from any illegal act of the victim as a direct consequence of his/her situation as trafficked; right to participation (reintegration in the society), nondiscrimination.

Secondly, it the right of every one that the inhuman act such as trafficking in Human Beings is prevented at all cost, and it is the duty of the state as well. To prevent trafficking state can come up with various policies, laws, regulations and so forth but the rights based approach in this phase means that in the name of prevention of trafficking nobody's rights can be compromised. For example, the freedom of movement, the right to leave one's country, the right to' legally migrate or the right to privacy hold particular significance in this context. (In this regard, Foreign Employment Act 2042 is an exemplifying instance of the undermining of rights based approach to trafficking in Nepal. According to Section 12 of the said Act for any women to seek foreign employment she has to get permission from her guardian, but this condition is not applied for Men. It seems the state made this law keeping in view the vulnerability of women that is women may get trafficked in the process. But such restriction for the purpose of preventing trafficking denied women their basic right to equality, work, movement etc.) The rationale behind this approach is that in the name of prevention governments may easily risk infringement upon the rights of the groups involved, in particular trafficked persons, female migrants and sex workers, hence to check such arbitrariness on the part of the state, rights based approach is most beneficial.

Concerning the issue of preventing trafficking, rights based approach has its own way. That is, as already mentioned that trafficking in human beings constitutes both a driver and an aftermath of human rights violations, so prevention of trafficking should also cohere with the rights of the people involved. As Recommended Principles and Guidelines on Human Rights and Human Trafficking puts it, "Strategies aimed at preventing trafficking shall address demand as a root cause of trafficking" (Principle 4, Recommended Principles and Guidelines on Human Rights and Human Trafficking, Report of the United Nations High Commissioner for Human Rights to the Economic and Social Council) so the rights based approach to prevent trafficking is to eliminate demand of trafficking. And it is quite obvious that whatever is the apparent reason for such demand but the ulterior and most universal reason is the lack of respect of Human Rights among people. For example, among total people trafficked in a year more than $80 \%$ are female and most of them are trafficked for the purpose of commercial sex,

(http://www.state.gOv/g/tip/rls/tiprpt/2005/) here apparent reason is that of sexual exploitation, which can only be fought effectively by eliminating the ulterior factor that of gender discrimination, inequality, disempowerment, poverty and so forth. So rights based approach seek to fight against trafficking by promoting the respect to human rights, under it respecting inherent dignity of all, promoting equality and nondiscrimination, empowerment of downtrodden etc. (Recommended Principles and Guidelines on Human Rights and Human Trafficking, Report of the United Nations High Commissioner for Human Rights to the Economic and Social Council, in its principle 5 also states, States and intergovernmental organizations shall ensure that their interventions consider the issues that lead to an increase in vulnerability to trafficking including inequality, poverty and all forms of discrimination) Moreover it is also true that once trafficked, people are more vulnerable of getting trafficked again when they fail to reintegrate in the society, so the prevention of trafficking through rights based approach also gives great importance to the reintegration of the victims in the society. The reintegration of victims in society in equal footing with others not only serves the purpose of saving victims but such inclusion can also result into formation of new policies in fighting trafficking, as the victims' experience can be very productive in determining in determining the anti-trafficking policies.

Hence the rights based approach to trafficking basically strengthens the anti-trafficking policy and process by addressing the issues of Human Rights of general public and those who have already been trafficked. Basically rights based approach seek to empower people, so that not only victim, find opportunity, voice and power to make a decent life and to integrate again in the society but also potential victims find themselves in equal footing with each other in participating, negotiating, influencing, controlling and holding accountable institutions that effect their life. 
Human trafficking (Control) Act defines trafficking of person as, Selling of person or taking anyone across the border with intention to sell that person, (Section 4 (a) and (b) of Trafficking in Human Beings (Control) Act 2043) similarly the Act has also defined trafficking as "an act of threat, incitement, and sale of women for the propose of prostitution.". It is clear by the definition that the Act is not by all means able to cover the ever expanding and intertwining concept of Trafficking. The definition includes exploitation of victims only in the form of their selling and sexual slavery, so fails to include other forms of exploitations such as forced labor, other forms of slavery, organ removal within the definition of trafficking. Similarly trafficking that takes place within Nepal is not covered by the definition. Therefore, this Act could in fact result in the situation of impunity for the grave breaches of Human dignity. Moreover, absence of provision for the assistance, protection, restitution of victims and prevention of trafficking has meant that the rights based approach to trafficking in Nepal is still a distant hope.

\section{Conclusion}

Trafficking is an abuse of human rights. During trafficking as the victim completely submits himself to the trafficker, the trafficked person is stripped off any existing right. Hence trafficking is the process inherently related to the violation of Human Rights. As a result, any measure taken to address the issue of trafficking must predominantly give priority to the protection and respect of rights. The moral approach that ridicules the trafficked, the crime control approach that only thinks about controlling crime and labor approach that blames unemployment can never resolve the actual problems associated with the trafficking. Accordingly, the effective approach is merely the one that takes into account the human suffering in trafficking, and mainly tries for the protection of human rights of the people trafficked rather than for the punitive law enforcement.

Normally law enforcement authorities are caught in the midst of the sensational news of trafficking that they barely give any attention to the victims, moreover the "bulk of government money on trafficking is spent currently for prosecutions and not for protection of rights. Very few resources have been allocated for establishing support systems for trafficking victims" and to add to the misery even the laws relating to trafficking pay little regard with the restitution of the rights of the victims.

In this situation of insensitivity towards the rights of the trafficked, trafficking in persons is getting out of control. As it has already been discussed that there lies the interlink between protection of the human rights of trafficked persons and the prevention and eradication of trafficking, the rights based approach serves in bringing this link in practice. Rights based approach to trafficking always keeps 'human person' at the center and with their empowerment, looks for the solution within the community. Rather than going behind any mechanistic and utopian theoretical solution to the problem, rights based approach empowers people to search the solution for themselves after getting assurance from the state regarding the protection of their rights. Hence through rights based approach sustainable solution of trafficking can be achieved. Similarly, when trafficking is approached in this way, dilemmas and ambiguity regarding the interconnection of Migration, Prostitution, Smuggling and Trafficking can be resolved once for all. Therefore, there is only one possible solution that can check trafficking, prevent trafficking, solve trafficking and serve trafficked, that is, the rights based approach to trafficking.

\section{References}

Azad, M. D. (2005). Ambiguities and Confusions in the Migration-Trafficking Nexus: A Development Challenge.

Foreign Employment Act 2042.

Marjan, W. (2004). An exploration of the meaning of a human rights based approach to trafficking, Alliance News.

Mary, R. (2000). Speech on "Women's Rights are Human Rights", Geneva 2000. Retrieved from www.unhchrch/htmPmenu2/womenpnh2000 hfml

Monique, H. (2004). Sex Trafficking in Nepal: Context and Process, Opportunities and Choices working Paper. Human Rights standards for the Treatment of Trafficked Persons, Global Alliance Against Traffic in Women

Muluki Ain Chapter on Trafficking of Human Beings Trafficking in Human Beings (Control) Act 2043.

Protocol to Prevent, Suppress and Punish Trafficking in Persons, Especially Women and Children Supplementing the United Nations Convention Against Transnational Organized Crime. (2000). [Palermo Protocol].

Recommended Principles and Guidelines on Human Rights and Human Trafficking, Report of the United Nations High Commissioner for Human Rights to the Economic and Social Council Save the Children Alliance (UNICEF), Trafficking of Women and Children in South Asia: Taking Stock and Moving Ahead, A Broad assessment of Anti- Trafficking initiatives in Nepal, Bangladesh and India, 1999.

Shahidulhaque, M. D. (2005). Right Based Approach to Human Trafficking. 
Status and Dimension of Trafficking within Nepalese Context, HDS and UNIFEM 2004.

The European Conference on Preventing and Combating Trafficking in Human Beings, the Brussels Declaration, 2002.

Trafficking in Persons and the smuggling in Migrants. (2005).

Trafficking in Persons Report, Released by the Office to Monitor and Combat Trafficking in Persons June 32005. http://www.state.gov/g/tir)/rls/tit>rpt/200SA

UN Secretary General's Report on "Trafficking in women and Girls" presented at the 58th Commission of Human Rights. (2002). (www.unhchr.ch).

Universal Declaration of Human Rights, 1948.

\section{Copyrights}

Copyright for this article is retained by the author(s), with first publication rights granted to the journal.

This is an open-access article distributed under the terms and conditions of the Creative Commons Attribution license (http://creativecommons.org/licenses/by/4.0/). 